\title{
A preliminary study using the cumulative gas production technique to compare the kinetics of different fermentations by use of standard substrates
}

\author{
BA Williams 1, SK Bhatia 2, H Boer 1, S Tamminga 1 \\ ${ }^{1}$ Dept. Animal Nutrition, Agricultural University, Haagsteeg 4, 6708 PM Wageningen, The Netherlands ; \\ ¿CCS Haryana Agricultural University, Hisar-125004, India
}

Until now, cumulative gas production (Theodorou et al, 1994, Anim Feed Sci and Technol, 48, 185-197) has been used to assess different feedstuffs, using a standard source of inoculum. However, gas production could also potentially be used to compare the kinetics of fermentations from rumen or hindgut of different species and/or resulting from different diets, by testing the different inocula with standard feedstuffs. This study was conducted to determine whether gas production could be used to assess the kinetics of such fermentations.

Substrates were : wheat straw (WS), rye grass (RG), soya bean hulls (SBH), wheat (W), maize (M), and soya bean meal (SBM). The inocula were: sheep rumen fluid (SRF-hay diet), cattle rumen fluid (CRF-grass silage diet), cattle rumen fluid (CRF-grass silage + concentrate diet), and cattle faeces (CFF-grass silage diet). Proximate and fibre analyses were performed on all substrates. Cumulative gas production was measured $(\times 4)$, for a period of 144 hours. At the end of fermentation, DM losses were measured and samples taken for VFA analysis. The yield of gas (Y) was calculated as $\mathrm{ml}$ total gas/g DM disappeared. Gas data were then fitted to the mono-phasic curve Cumvol $=\mathrm{A} /\left(1+\left(\mathrm{C} /\right.\right.$ Time $\left.^{\mathrm{B}}\right)$ of Koops et al (1995). An analysis of variance of the data (curve parameters and DM Losses) showed a highly significant interaction for substrate and inoculum $(P<0.01)$. CFF had the poorest fermentative ability with the lowest \% DM loss, lowest gas production (A), and the longest halftime (C). However, CFF ranked the substrates in roughly the same order as SRF, which is currently used as the standard inoculum in many centres. The patterns of degradation of the substrates did follow predictions to some extent; eg WS was the most poorly degradable in terms of gas production and DM loss for all inocula, and had a consistently high gas yield. $M$ and $W$ were most similar, both in terms of their gas profiles and yields, and their DM losses. Most variation was seen in the ranking of $\mathrm{RG}, \mathrm{SBM}$, and $\mathrm{SBH}$, in terms of their gas profiles (though not DM Loss) for the 4 inocula. SBM was the most interesting substrate, having a combination of low gas, and low yield, yet a high VFA concentration.

It was concluded that cumulative gas production has potential as a means to compare fermentations from different sources. However, a routine analysis of VFA at the end of the test period is recommended, to allow the detection of more subtle differences between the samples.

\begin{tabular}{|c|c|c|}
\hline Mean Values & $A(m l)$ & $\mathrm{B}(\mathrm{ml} / \mathrm{h})$ \\
\hline \multicolumn{3}{|l|}{ Inoculum } \\
\hline SAF (grass) & 214.4 & 2.13 \\
\hline CRF (silage) & 201.3 & 2.07 \\
\hline CRF (silage + conc) & 227.0 & 2.11 \\
\hline CFF & 193.1 & 2.03 \\
\hline MSD $(P<0.05)$ & 8.30 & 0.14 \\
\hline \multicolumn{3}{|l|}{ Substrate } \\
\hline Wheat Straw & 164.8 & 1.94 \\
\hline Rye Grass & 208.0 & 1.75 \\
\hline Soya Bean Hulls & 235.3 & 2.16 \\
\hline Wheat & 233.2 & 2.36 \\
\hline Maize & 240.0 & 2.43 \\
\hline Soya Bean Meal & 167.7 & 1.95 \\
\hline $\operatorname{MSD}(P<0.05)$ & 11.2 & 0.18 \\
\hline
\end{tabular}

$\begin{array}{ccrc}\mathrm{C}(\mathrm{h}) & \mathrm{Y}(\mathrm{ml} / \mathrm{g}) & \% \mathrm{DM} \text { Loss } & \text { Total VFA(mM) } \\ 24.7 & 301.0 & 87.9 & 68.0 \\ 24.3 & 291.2 & 87.6 & 67.3 \\ 25.8 & 331.2 & 87.8 & 72.2 \\ 31.0 & 286.1 & 85.5 & 69.7 \\ 2.23 & 15.1 & 1.43 & - \\ & & & \\ 43.2 & 325.3 & 63.6 & 52.5 \\ 21.9 & 319.2 & 82.3 & 67.1 \\ 30.9 & 332.9 & 88.6 & 77.1 \\ 19.9 & 305.4 & 96.2 & 69.7 \\ 24.3 & 316.0 & 94.9 & 75.6 \\ 20.3 & 216.0 & 97.4 & 73.8 \\ 3.0 & 20.7 & 1.94 & - \\ & & & \end{array}$

